I Fundação Getulio Vargas do Rio de Janeiro,

Escola de Ciências Sociais, Brasil

joao.maia@fgv.br

João Marcelo E. Maia'

\title{
OS SENTIDOS DA TRADIÇÃO: UM ESTUDO DE CASO NO PENSAMENTO SOCIAL BRASILEIRO
}

Este artigo dedica-se a avançar uma hipótese que dê conta da diversidade da obra de Elide Rugai Bastos por meio de uma análise de algumas de suas obras principais no campo do pensamento social brasileiro. Não é fácil escrever sobre esta obra. A presença constante da autora nos diferentes fóruns intelectuais das ciências sociais brasileiras produz um sentimento de familiaridade enganoso, como se sua obra fosse de simples decifração. Contudo, uma leitura mais detida dos livros e dos textos produzidos pela autora revela uma diversidade de interesses e objetos, que vão das Ligas Camponesas (Bastos, I984) a intelectuais conservadores, como Octávio de Faria (Bastos, 20 Io), passando pelo marxismo de Georg Lukács e Lucien Goldmann. Minha hipótese é a de que Elide localizou nos elementos da tradição brasileira um fator fundamental para o desvendamento da dinâmica do processo social capitalista em uma sociedade periférica como a brasileira. Tal fato explica por que uma intelectual que estabeleceu criativo diálogo entre sociologia e marxismo dedicou-se com tanto afinco à análise do pensamento de intelectuais notoriamente conservadores, identificados não necessariamente com a transformação radical ou a vanguarda da modernização, mas com forças que, se não eram explicitamente resistentes ao aburguesamento, mostravam-se, no mínimo, reticentes diante do processo.

O artigo divide-se em três seções e uma breve conclusão. Com o objetivo de evidenciar a construção do problema abordado, na primeira seção, intitulada "Pistas biográficas", procuro descrever meu percurso nas fontes primá- 
rias, oferecendo também uma breve análise das influências intelectuais da autora. Na segunda seção, dedico-me a uma análise dos textos de Elide sobre Gilberto Freyre, por entender que eles ocupam lugar de relevo em sua obra e demonstram de forma mais clara o argumento sustentado neste artigo. Já na terceira parte, analiso os textos da autora sobre outros pensadores conservadores, com destaque para suas análises sobre Paulo Augusto de Figueiredo e Octávio de Farias. Estas análises reforçam e complementam aspectos do pensamento brasileiro vislumbrados na obra de Freyre, e que se referem aos sentidos de tradição assumidos nos escritos de tais intelectuais. Finalmente, na conclusão, aponto como os estudos da autora relacionam-se a inferências mais gerais, tanto sobre o processo de modernização capitalista no Brasil, como sobre a própria forma adequada para desvendá-lo.

\section{PISTAS BIOGRÁFICAS}

Meu percurso iniciou-se a partir das minhas próprias recordações como pesquisador nesse campo de estudos. Lembrava-me especialmente de um encontro da Sociedade Brasileira de Sociologia, em 2003, realizado na Unicamp, em que pude assistir a sessões do grupo de trabalho de Pensamento Brasileiro e ler alguns exemplares da revista Trapézio, editada pelo Centro de Estudos Brasileiros, que era então coordenado por Elide Rugai. Depois desse evento, pude conhecer também os trabalhos de seus orientados, e chamou-me atenção a coerência teórico-metodológica dessas pesquisas, que invariavelmente utilizavam os conceitos de forma e de processo para lidar com o problema dos nexos entre classes, cultura e experiência social. Penso, em especial, nos trabalhos de Mariana Chaguri (2009) e Mário Augusto Medeiros da Silva (2013).

Com estas recordações em mente, parti para a leitura mais detida dos trabalhos da autora. Minha primeira fonte foi um vídeo da série "Conversas com o autor", disponibilizado no portal da Anpocs, no qual Elide fala de sua trajetória profissional e intelectual (Bastos, 2007). Duas coisas me chamaram a atenção: em primeiro lugar, sua experiência como docente na PUC-SP, instituição na qual foi colega de Florestan Fernandes, Celso Furtado, Octavio Ianni e Chico de Oliveira, partilhando a vida profissional com alguns dos mais conhecidos cientistas sociais brasileiros. Além disto, também reparei na sua dissertação de mestrado em Ciência Política, dedicada ao estudo das Ligas Camponesas, publicada em livro pela editora católica progressista Vozes (Bastos, I984). Um segundo documento bem significativo foi uma entrevista conduzida por Lilia Schwarcz e André Botelho, publicada na revista Lua Nova, na edição intitulada "Simpósio: cinco questões sobre o pensamento social brasileiro", em que diferentes pesquisadores analisavam a formação deste campo de pesquisa e suas próprias biografias (Schwarcz \& Botelho, 20I I). Naquela entrevista, Elide menciona alguns trabalhos considerados fundamentais, entre 
os quais figuram livros de Lukács e Goldmann, autores que parecem sempre acompanhá-la.

Essas primeiras fontes indicavam uma intelectual progressista, socializada na cultura intelectual da esquerda acadêmica paulista (Lahuerta, I999) e em forte diálogo com a análise marxista da cultura. Note-se que a aproximação com o marxismo não esgota a formação intelectual da autora, em que o recurso à obra de Karl Mannheim foi também fundamental, especialmente por conta da relação entre ideias e experiência social e pela interpretação mannheimiana sobre o pensamento conservador. Tal formação pode ser entendida como expressão de uma sensibilidade intelectual próxima àquela associada à chamada "escola paulista de sociologia", em que o marxismo foi assumido não como a ciência exclusiva do operariado, mas como uma teoria sociológica crítica em diálogo com outras. Ressalta-se que não é ponto pacífico entre intérpretes contemporâneos nem a existência de uma "escola" propriamente dita, nem o tipo de vinculação com o marxismo. Na hoje clássica análise de Gabriel Cohn (I978), centrada mais propriamente na figura de Florestan Fernandes, tratava-se de um "ecletismo bem-temperado", em que Marx era incorporado como um dos clássicos da ciência social, mas poderia conviver com Weber e mesmo com conceitos funcionalistas - como se vê na fatura brilhante de "A integração do negro na sociedade de classes" (Fernandes, I965). Já a interpretação de Maria Arminda Arruda (I995) explora com mais vagar a experiência intelectual dos discípulos de Florestan, enfatizando a formação do primeiro seminário de leitura de Marx e a centralidade dos "novos" marxismos para a construção de análises sofisticadas dos padrões contraditórios do desenvolvimento capitalista brasileiro. De qualquer modo, é possível sustentar que este marxismo - mais ou menos eclético - distanciava-se da ortodoxia leninista e era pensado a partir da produção de um projeto sociológico.

Contudo, embora a formação intelectual da autora possa ser compreendida à luz da heterodoxia da escola paulista, sua escolha de objetos não foi necessariamente comum, denotando uma inflexão original. Ao mergulhar nas obras escritas ou organizadas por Bastos no campo do pensamento brasileiro, deparei com os seguintes nomes que foram objeto de sua atenção e curiosidade: Gilberto Freyre, Oliveira Vianna, Paulo de Augusto Figueiredo e Octávio de Faria. É claro que Florestan Fernandes também foi um tema constante de suas reflexões (Bastos, 2002), mas a composição do time não deixa dúvidas: o pensamento conservador é motivo de interesse principal desta intelectual com uma sólida bagagem marxista e progressista.

Depois deste percurso mais propriamente biográfico, foi necessário verificar as fontes intelectuais do pensamento da própria Elide. Neste artigo, opto por explorar dois conceitos para explicar a questão colocada acima: tragédia e processo social; o primeiro, um conceito histórico-literário, o segundo, um conceito analítico. No primeiro caso, a referência fundamental são os es- 
tudos de Lukács sobre as relações entre literatura e sociedade. Em seu conhecido texto sobre o tema, o marxista húngaro mostra como tal forma estética funda-se na tentativa de identificação entre o herói e a comunidade da qual faz parte, visando a uma possível transcendência num mundo ameaçado pela fragmentação e pelo individualismo (Lukács, 2009 [I9I6]). A grande questão que motiva os trágicos modernos seria, portanto: como reatar a comunhão dos indivíduos com sua essência humana, que outrora estava garantida pela comunidade existencial da tradição, e que depois do século XVI parecia ter se quebrado e fragmentado? Esta questão e o conceito de tragédia serão fundamentais no estudo de Bastos sobre o escritor Octávio de Faria, autor de uma portentosa obra dividida em vários volumes e intitulada, justamente, "A tragédia burguesa".

O conceito de processo, por sua vez, busca superar uma análise marxista redutora, que teimaria em aprisionar o mundo social numa relação mecânica desprovida de mediações. Tal conceito liga-se, portanto, a uma análise da totalidade, categoria reclamada por Lukács no seu clássico livro de I923 (Lukács, 2003) como grande eixo criativo do marxismo e elemento que o singularizaria em relação a outras formas de análise do social. Isto é, a análise marxista do processo implicaria conceber a dimensão total da vida social, entendida como conjunto de mediações complexas que não podem ser entendidas pela separação analítica de instâncias ou fatores supostamente factuais e empíricos. Não à toa, a análise que Lukács faz do grande romance europeu valoriza exatamente os escritores que logram traduzir em termos formais a dinâmica própria da vida burguesa capitalista, marcada pela circulação da mercadoria e pela individualidade em desencontro com o mundo e pela complexa teia de determinações que marcam o social (Lukács, I968). Para este autor, o grande romance realista não é aquele que reifica este mundo, ao apresentá-lo detalhadamente por meio de descrições de aspectos isolados do cotidiano, mas, sim, o que consegue retratar o movimento do real por meio da apreensão de suas leis de conexão e mediação. Neste sentido, a totalidade estilhaçada da vida moderna seria recomposta pela arte por meio da forma, que reconectaria tragédia e processo social.

Note-se que o diálogo criativo com o marxismo estabelecido por Bastos não se esgota no par Lukács-Goldmann - embora este par seja importante para a própria geração formada por Florestan Fernandes, como relata Maria Arminda Arruda em seu texto sobre a escola paulista (Arruda, I995). Bastos também recorreu à obra de Gramsci para pensar o problema da vida intelectual em formações capitalistas, e, em especial, para refletir sobre o lugar dos intelectuais orgânicos em tal processo. Como se verá ao final, a mediação de Gramsci é fundamental para entender a perspectiva mais geral da autora sobre esses temas, ao passo que os conceitos aqui trabalhados respondem mais diretamente ao tema proposto neste artigo. 
Ora, mas como esse arsenal, criado para dar conta das vicissitudes da experiência burguesa no Velho Mundo, pode ser empregado para a análise das ideias e da cultura no Brasil, este canto periférico do mundo, no qual o elemento burguês se afirmou de forma lenta e negociada, como já mostrou boa parte da melhor sociologia brasileira (Fernandes, I975; Werneck Vianna, 1997)? Na obra de Elide revela-se justamente como a dinâmica do processo social brasileiro implica um mergulho no sentido de nossa tradição, ou melhor, nos elementos intelectuais, culturais e sociais relacionados à conservação. Neste estranho movimento reside uma das grandes singularidades nacionais: para entendermos o processo social e a dinâmica da mudança, há que decifrar as forças que lhe são opostas.

\section{OS SENTIDOS DE PROMETEU}

Pode-se dizer que o desvendamento do processo social brasileiro ganhou um mapa nas obras Gilberto Freyre e o pensamento hispânico (Bastos, 2003) e As criaturas de Prometeu: Gilberto Freyre e a formação da sociedade brasileira (Bastos, 2006a), resultados de pesquisa vinculada à tese de doutorado defendida na PUC-SP em I986, e vencedora do I ${ }^{\circ}$ Prêmio Nacional de Ensaios/Gilberto Freyre, em 2004-2005. Estas obras tiveram grande importância na retomada dos estudos freyreanos, juntando-se a outros trabalhos de referência, como a tese de doutorado de Ricardo Benzaquen de Araújo, defendida em meados da década de I990 no Museu Nacional/UFRJ (Araújo, I994).

São muitas as possibilidades de interpretação destes escritos de Bastos, mas gostaria de destacar três temas fundamentais para sua análise sobre Freyre e para o próprio entendimento da hipótese sustentada neste artigo: a) o sentido do patriarcalismo na análise sociológica de Freyre; b) a decadência como chave de leitura da transição modernizadora; e c) a inscrição não ocidental da sociedade brasileira no mundo moderno, tema mais propriamente explorado nas obras sobre o pensamento hispânico.

Ressalto que a trinca de questões que destaquei acima não são as mesmas explicitamente mobilizadas pela autora. Logo no início da introdução de As criaturas de Prometeu, a autora destaca três pontos da obra freyreana que lhe parecem fundamentais: são eles o patriarcalismo, a interpenetração de etnias e culturas, e o trópico (Bastos, 2006: I I). Não se trata de negar a interpretação da própria autora, mas, neste artigo, meu objetivo não é interpretar Freyre, e, sim, dialogar com a análise feita por Elide a seu respeito. Ou seja, sustento que há nos textos da autora uma riqueza de significados que estabelece conexões de sentido não reivindicadas explicitamente, mas que podem ser inferidas a partir de um embate criativo com a escrita. Tal ângulo de interpretação é inspirado nas formulações de LaCapra (1980) sobre história intelectual, em que este autor defende a possibilidade de o analista extrair do texto camadas de 
significados produzidos a partir de um diálogo com a obra em questão, evitando a fixação de um sentido supostamente congelado no momento da escritura dos textos clássicos.

LaCapra constrói seu argumento a partir da distinção entre os aspectos documentais e "work-like" de um texto a ser estudado. No primeiro caso, trata-se do aspecto literal e informativo de um objeto textual, isto é, sua conexão com uma realidade empírica específica. Já “work-like” refere-se aos aspectos não redutíveis ao universo empírico e que permanecem no texto como potência criativa a ser cultivada pelo diálogo interpretativo, que se dá numa relação temporal. LaCapra sustenta que interpretações por demais focadas no primeiro aspecto tratam o texto como uma entidade homogênea portadora de um significado estável, que poderia ser rastreado em quaisquer passagens e remetido a "blocos" de ideias mais amplas. Seu interesse, portanto, está em explorar o segundo aspecto, que permite ao intérprete perseguir pistas não plenamente desenvolvidas pelo próprio autor original, e que instituem diferenças e tensões que podem ser produtivas intelectualmente.

Adoto tal perspectiva ao explorar alguns aspectos contidos na obra de Bastos sobre Freyre que não são necessariamente dominantes numa primeira leitura, mas que podem ganhar densidade ao se conectarem com as preocupações teóricas citadas na primeira seção, que, por sinal, também não são as únicas que marcaram a formação da autora. Ou seja, explorar uma nova ordem de relevância no texto original me permite destacar um aspecto relevante do diálogo estabelecido por Bastos entre sociologia e marxismo. Trata-se, portanto, de potencializar uma chave de leitura possível, mas seguindo certo método.

Como dizia, o conceito de patriarcalismo ocupa lugar central na interpretação da autora. No capítulo 4 de As criaturas de Prometeu, Bastos mostra como tal conceito ganha seu contorno definitivo na obra Sobrados e mucambos. Neste livro, Freyre se deteria com mais vagar no papel de acomodação exercido pela família ampliada brasileira, chefiada pelo grande senhor de engenho. Fruto da colonização portuguesa, esse modelo de organização social implicaria uma experiência social organizada não a partir do indivíduo burguês, de seu correspondente núcleo familiar e da consequente separação entre as esferas pública e privada, mas, sim, a partir da família ampliada, fenômeno típico da nossa colonização. Essa família, composta por filhos legítimos e naturais, escravos domésticos e toda a gama de protegidos e favorecidos, seria comandada pelo pater familias, produzindo uma trama social que combina coesão e profunda desigualdade.

Conforme bem observa Elide, Freyre atribui um valor político ao patriarcalismo. Em momentos decisivos da formação brasileira, a força plástica e acomodatícia do patriarcado ajudaria a manter as tensões equilibradas, ajustando as forças liberais e conservadoras e freando as rupturas violentas. Nas palavras da própria autora, 
o que Gilberto Freyre encaminha como tese é que o patriarca teve uma sabedoria que o Estado impessoal não pudera ter. A conciliação só se torna possível na medida em que entra em jogo a compreensão daquelas relações tradicionais e singulares que marcam nossa formação. O setor capacitado a essa compreensão é aquele "treinado" nas relações patriarcais (Bastos, 2006a: 104).

Ao mesmo tempo, a centralidade do patriarcado permitiria a Freyre destacar a força dos indivíduos e dos tipos sociais situados fora do processo clássico de modernização burguesa - o escravo, a mulher e a criança, personagens que ganham destaque na interpretação de Elide. Estes tipos terminariam por imprimir uma feição peculiar ao mundo social brasileiro, afastando-o do figurino mais clássico do homem burguês europeu, forjado na experiência do trabalho industrial, do comércio e da vida civil-urbana.

Note-se também como a intérprete consegue, desta maneira, conectar o método freyreano aos pressupostos existenciais acalentados pelo próprio autor. Isto se dá porque a análise detida da vida privada e cotidiana, marca da metodologia do sociólogo pernambucano, corresponde a uma valorização desse povo intra-histórico, espécie de magma que funciona para Freyre como promessa civilizatória. Em As criaturas de Prometeu, a autora explora este ponto em vários trechos, e não apenas no capítulo IV. Assim, a discussão de Bastos sobre os espaços domésticos e a centralidade da casa na escrita freyreana estão diretamente relacionados ao tema do patriarcado. Do mesmo modo, a própria interpenetração de culturas, eixo destacado pela própria autora, é articulada no capítulo $\mathrm{V}$ ao processo de acomodação de conflitos que marcaria a formação brasileira, e que seria expressão de uma sociedade patriarcal. Nas palavras da autora:

Segundo o autor, o processo de acomodação no campo cultural ao mesmo tempo requer e é produto do amálgama biológico e étnico. Tal processo teria sido realizado, no Brasil, pela miscigenação: primeiramente, dos portugueses e espanhóis com os árabes e judeus; posteriormente, destes mestiços com os índios e negros. Por esse motivo as tensões na sociedade brasileira não se explicitam em conflitos que emergem em movimentos sociais (Bastos, 2006a: I I4).

Já o segundo ponto, relativo ao problema da decadência, chama a atenção pela originalidade, já que há uma tendência em localizar na obra de Freyre certa celebração do processo civilizador brasileiro, por mais que se reconheça no sociólogo pernambucano interpretações atentas aos matizes e às ambiguidades de nossa experiência social. Como já afirmei, na introdução de sua obra a autora não elenca a decadência como um dos três grandes eixos de interpretação dos textos de Freyre. Porém, no capítulo VII de As criaturas de Prometeu, intitulado justamente "Variações de Prometeu", Elide Bastos afirma: "O que poderíamos considerar como temática privilegiada de Gilberto Freyre? Como já foi dito, a transição ao moderno com dois elementos presentes no processo: a decadência e a sobrevivência" (Bastos, 2006a: I74). Em seguida, a autora mos- 
tra como a atenção dada por Freyre a estes temas relaciona-se com a própria metodologia do sociólogo pernambucano, orientada pela análise do tempo longo das relações sociais primárias e pela centralidade dos mecanismos pessoais de ajustamento entre os indivíduos. Ou seja, uma sociologia preocupada com o mundo vivido pelos agentes desembocaria numa análise da sociedade brasileira pautada na longa duração das estruturas familiares e íntimas dos brasileiros. Em vez de privilegiar as rupturas políticas e as mudanças institucionais, Freyre matiza tal ponto ao relacioná-lo com a sobrevivência dos modos de vida tradicionais, que, a despeito de perderem força com a modernização social, continuam a exercer um lento, mas persistente efeito de ajustamento no processo de aburguesamento.

Ao insistir neste tema, a autora lê Freyre como um intérprete situado no coração de uma grande transformação brasileira, que rompia com os limites da ordem do Antigo Regime nativo e ameaçava produzir desagregação e individualismo predador. Bastos mostra como os grandes livros de Freyre, em especial sua trilogia da década de I930, apanham o processo de desagregação da ordem patriarcal em pleno movimento constitutivo, embora tal desagregação nunca se dê de forma plena, como num jogo de soma zero. Cito a passagem, que me parece chave:

O estudo da família patriarcal em Gilberto Freyre tem duas faces. De um lado permite perceber uma transição histórica - do mundo comunitário ao societário; das formas de prestação pessoal ao contrato; da organização da vida através de grupos primários à divisão social do trabalho; das relações entre personalidades plenas a relações impessoais no seio de instituições; das relações face-a-face à formação de grupos secundários. De outro, embora constatando uma transformação nas relações humanas e a secularização dos valores, procura mostrar que a comunidade nunca se apaga, continua sobrevivendo nos poros da sociedade (Bastos, 2006a: I84).

O uso da palavra "poros" não me parece gratuita ou decorrência de simples efeito poético. Bastos está apontando para o fato de que a sobrevivência das relações comunitárias implica um deslocamento do lugar do patriarcalismo. Se outrora a família ampliada foi o cerne da vida nacional, operando como núcleo de sustentação política, após o processo de re-europeização do século XIX essa forma de sociabilidade passou a exercer efeitos mais sutis, embora ainda disseminados. Antes o coração da vida político-social brasileira, a família patriarcal continua espalhada pelo corpo nacional, agora revestindo o tecido desse corpo de forma epidérmica, embora não menos vital.

Contudo, a despeito dessa vitalidade e de tal sobrevivência - que Bastos corretamente relaciona a um programa político-filosófico alternativo ao liberalismo burguês, portanto portador de forte valor normativo -, parece-me claro que o patriarcalismo também se associa à decadência, e que tal processo tem lugar importante no pensamento da autora sobre Freyre. A autora argu- 
menta que, especialmente em Sobrados e mucambos, seria possível vislumbrar o diagnóstico do autor a respeito do lento esboroamento da velha ordem patriarcal e da consolidação de relações pessoais mercantis e menos comunitárias. Tal processo teria efeitos culturais, sociais, políticos e econômicos, além de ter ritmos diferentes, a depender da região do país. Interessante notar como no capítulo IV, já referido acima, a subseção "Processo de decadência" ocupa mais páginas do que o trecho dedicado à formação e à consolidação do patriarcalismo. Tal fato se explica porque os tempos desses processos se interpenetram. Nas palavras da própria autora: "O enfraquecimento do patriarcalismo, para Gilberto Freyre, deu-se lentamente. Nesse processo, perdeu espaço o poder privado familista e alargou-se e consolidou-se o poder público. A família transformou-se e surgiu o Estado. A alteração da casa é testemunha e símbolo desse processo." (Bastos, 2006a: 94, grifos da autora).

Como se tal evidência não fosse suficiente, Bastos afirma ao concluir a seção: "Segundo Gilberto Freyre, é porque os tempos de consolidação e decadência se cruzam que o método histórico convencional torna-se insuficiente para dar conta da análise da família patriarcal no Brasil bem como o convencionalismo sociológico" (Bastos, 2006a: ı08).

Como se vê, a decadência do patriarcalismo não deve ser vista como um desaparecimento, mas como uma mudança do seu lugar social e um ajustamento de algumas de suas características a uma sociedade urbana e modernizada. Sustento que o tema ocupa espaço considerável na obra de Elide Bastos porque tal processo relaciona-se a outra questão, que diz respeito ao lugar da experiência brasileira no quadro mais geral do mundo moderno. A autora equaciona a questão associando o patriarcalismo a certo orientalismo, marcado pelas ideias de trópico e hispanidade. Vejamos inicialmente o debate sobre o trópico.

Em As criaturas de Prometeu, a autora dedica o capítulo VI ao tema do trópico. Nele, Bastos articula dois argumentos sobre a relação entre espaço e sociedade. O primeiro diz respeito à ênfase de Freyre na ecologia dos trópicos, que o leva a afirmar a centralidade da região na conformação de uma sociedade diversa e costurada pelo tema da conciliação, fato que é visto como um valor positivo pelo autor pernambucano.

Após dissecar as referências teórico-filosóficas que movem Freyre na direção de uma reflexão ecológica sobre a existência humana, Bastos conduz então o leitor a uma investigação breve sobre os textos freyreanos sobre o Nordeste. Nessas passagens, demonstra como o sociólogo articula análises da produção agrícola e seus efeitos sobre a terra a inferências sociológicas sobre os tipos humanos que ali habitam e sobre as dinâmicas culturais que se processam na região. Nas palavras da autora, "Para Gilberto, mais que uma região geográfica, o Nordeste é um segredo: segredo de convivência, conciliação, equilíbrio entre antagonismos, plasticidade, sabedoria política" (Bastos, 2006a: I59, grifo da autora). 
O segundo argumento relaciona-se ao trópico como espaço de ligação entre Oriente e Ocidente, o que inscreveria o Brasil em uma geografia civilizatória não puramente ocidental e/ou burguesa. Isto porque o trópico é o locus da civilização do açúcar e do patriarcalismo, espaço no qual os laços sociais se organizam a partir de outra temporalidade e distintas fronteiras. Se a Europa conjugava civilização industrial, cidades e classes orientadas por interesses antagônicos, o Brasil amalgamaria civilização agrícola, trópico e grupos amarrados pela ordem patriarcal. No dizer da autora, "Segundo Gilberto, o tempo tem outra duração. Duração que passa pelo clima, pela influência oriental na formação brasileira, pela recusa ao industrialismo e ao burguesismo" (Bastos, 2006a: I62). Como se vê, Bastos localiza em Freyre uma articulação entre tropicalismo e experiência não ocidental, o que tem impacto, inclusive, sobre os esquemas mentais que marcariam a subjetividade dos brasileiros. Tal ponto é explorado com mais precisão na obra sobre pensamento hispânico, que analisarei brevemente a seguir.

Em Gilberto Freyre e o pensamento hispânico (Bastos, 2003), a autora mostra como o problema da decadência espanhola, vivenciado pela famosa geração de I898, transformou-se numa fonte de inspiração para gerações de intelectuais que procuraram lidar com a inscrição da Espanha no mundo moderno. $\mathrm{O}$ dilema entre tradição e europeização teria sido sentido fortemente por esse grupo, e a autora é hábil ao mostrar como as diferentes gerações de intelectuais espanhóis partiram exatamente do problema regional para entender a necessidade de produzir uma vida moderna que respeitasse a diversidade das formas locais de vida e resistisse à uniformização do mundo. Tomando como fonte a marginália anotada de Freyre, Bastos examina até que ponto o sentido da tradição recuperada em Freyre é tributária desse pensamento espanhol, e termina por operar como passaporte para o autor delinear o horizonte da modernidade orientalizada brasileira.

No capítulo II deste livro, intitulado justamente "O retorno às tradições", Bastos analisa os escritos regionalistas de Freyre, publicados na década de I920, à luz das reflexões de intelectuais espanhóis da geração de I898. Ela afirma:

[...] creio ser possível afirmar que uma das grandes influências recebidas por Gilberto em relação a esse tema seja a de Ángel Ganivet, escritor espanhol já referido, pertencente à geração de 98 . Dois pontos principais que atravessam sua reflexão naqueles artigos ressoam as ideias desse intelectual: denuncia a imitação, apontando os resultados desastrosos da mesma; recusa um progressismo sem critério que mata as tradições. (Bastos, 2003: 46)

No capítulo III, cujo título é "Oriente e Ocidente", Bastos leva o argumento adiante, rastreando o tema do orientalismo da cultura brasileira na obra de Freyre e demonstrando sua conexão de sentido com o debate ibérico sobre a natureza fronteiriça da cultura peninsular. No capítulo, a autora destaca os temas da decadência, do tempo tríbio (e não vazio e homogêneo) e do ciclo da 
vida, e do iberismo, tomados como eixos principais da reflexão sobre o lugar do Brasil no mundo. Assim, se o mundo burguês estaria em profunda crise moral e espiritual, os povos mestiços e "rústicos" representariam a possibilidade de uma vivência nova, criativa e plena de possibilidades civilizatórias. Ao diferenciar tal postura da posição decadentista europeia, a autora afirma:

Isto é, quando propõe, para a solução da crise que atravessa a sociedade brasileira, um retorno às tradições, não está lamentando o abandono das tradições ocidentais, cristãs etc., mas sim aponta para a crise como resultado da paulatina perda dos elementos híbridos, ocidentais e orientais, portugueses e árabes, europeus e africanos, que marcam nossa formação e que, segundo ele, sempre foram a garantia do equilíbrio social. É importante lembrar que o autor busca as raízes dessas tradições fora do mundo ocidental, ou não apenas no mundo ocidental. (Bastos, 2003: 77)

Como se vê, tudo se passa como se Brasil e Espanha fossem sociedades nas quais o aburguesamento permanecesse travado, ou fosse sentido como uma impostura a ameaçar o senso de comunidade nacional, que deveria ser atualizado por outros caminhos que não o do mimetismo. Nota-se, aqui, como o problema da tragédia, embora não nomeado de forma explícita, surge como grande fatura estética. Sustento que é exatamente este movimento que explica o interesse da autora pelos pensadores conservadores, e que lhe permitirá atinar com as matizes de tal doutrina e verificar os sentidos assumidos pela tradição no processo de modernização brasileiro.

\section{OS SENTIDOS DA TRADIÇÃO}

Nesta seção, gostaria de me concentrar especificamente em dois textos de Elide Bastos que analisam o pensamento conservador brasileiro, mas que tomam como objetos dois intelectuais menos visitados pelos estudiosos do que o consagrado Gilberto Freyre. Refiro-me ao artigo da autora sobre o escritor católico Octávio de Faria, publicado na obra coletiva "Revisão do pensamento conservador. Ideias e política no Brasil" (Ferreira \& Botelho, 20Io) e no texto sobre o intelectual estado-novista Paulo Augusto Figueiredo, publicado na coletânea Intelectuais e Estado (Ridenti, Bastos \& Rolland, 2006).

No texto "Octávio de Faria e a tragédia burguesa" (Bastos, 2010), a autora faz uma leitura de alguns temas do ciclo intitulado Tragédia burguesa, composto por quinze romances publicados entre I937 e I979. Apoiada nas concepções de tragédia e romance moderno que lhe foram caras ao longo de sua trajetória intelectual, Elide procura demonstrar como Octávio de Faria poderia ser caracterizado como defensor de um tradicionalismo tardio, que teria representado uma facção perdedora no processo modernizador desencadeado em I930.

Na sua análise de alguns personagens e enredos do ciclo, a autora mostra como o tema da regeneração é constantemente reafirmado pelo escritor, 
que vê de forma crítica a consolidação do individualismo e do chamado "espírito burguês". Nas palavras de Elide, "A ideia da regeneração da sociedade pela destruição do espírito burguês através da difusão do espírito cristão e da aspiração do Deus-vivo consolida-se como objetivo da Tragédia" (Bastos, 20ı: 306).

Ao final, Elide mostra como o furor tradicionalista de Octávio de Faria, representante de certo estado de espírito de algumas hostes católicas das décadas de I920 e I930, não encontrou base social suficiente para converter-se em programa político consequente. Assim, é interessante como a autora convoca Freyre nas páginas finais, justamente para produzir um espelhamento que lhe permita avaliar o sentido da tradição na experiência brasileira. Isto é, se o escritor católico representava uma visão que opunha firmemente tradição a aburguesamento, Freyre sintetizaria o polo conservador vencedor, capaz de localizar uma tradição mais "doce" e capaz de se ajustar ao mundo burguês emergente. Cito a autora:

Forçando o argumento podemos dizer que o tradicionalismo de Octávio é perdedor no processo social. Ao contrário, o de Gilberto Freyre é vencedor, na medida em que fornece elementos fundamentais à conciliação que se processa em I930, articulando os velhos e novos setores sociais: suas propostas, principalmente em torno da "democracia racial", do "regionalismo" e do "patriarcalismo" transformam-se em cultura política. (Bastos, 2010: 308)

Pode-se dizer que tal cultura política converteu-se, após I937, em razão autoritária de Estado. E, por isso, acho fundamental complementar esta análise do sentido da tradição no processo social brasileiro com uma breve interpretação do curto texto de Elide sobre um intelectual fundamental na operação estatal do Estado Novo. Em "Paulo Augusto Figueiredo e o pensamento autoritário no Brasil” (Bastos, 2006b), a autora analisa a produção deste intelectual tido como menor, e que interveio na vida brasileira tanto nas décadas de 1930 e I940, como no período do regime militar, nas décadas de ig60 e i970. Elide mostra como Paulo de Figueiredo aproximou-se da obra de Ortega y Gasset em sua crítica ao liberalismo moderno, o que o levou a defender o Estado Novo e o papel ativo dos intelectuais na organização da cultura nas páginas da revista Cultura Política. A autora também analisa a visão conservadora do autor a respeito das hierarquias e desigualdades sociais, mostrando como a defesa da urgência da questão social não implicava necessariamente uma abordagem progressista do tema.

Interessante notar no texto de Elide como nos dois períodos históricos nos quais se situa a obra do autor estudado é possível localizar a defesa da dimensão conformadora do Estado, agente que deveria modelar a sociedade e ser o locus de interpretação geral da cultura brasileira. Tal formulação, comum a numerosos outros pensadores brasileiros, evidencia uma das peculiaridades de certo ramo do pensamento conservador nacional. Longe de ser simples resistência, tal conservadorismo opera em conjunção com os agentes e as for- 
ças da modernização, emperrando seus impulsos mais transformadores e imprimindo-lhes o sentido da tradição brasileira, vista como naturalmente hierarquizada e harmônica.

Como se vê, estes dois textos permitem à autora investigar outras matrizes do pensamento conservador brasileiro, evidenciando, portanto, o quanto a tradição pode guardar significados distintos para os intelectuais que a empunhavam como bandeira. Além disto, estes diversos sentidos da tradição relacionavam-se ao próprio andamento da modernização burguesa brasileira, cujas peculiaridades podem nos ajudar a entender por que Elide Bastos dedicou-se com tanto afinco à investigação da obra de Gilberto Freyre, situando-o de forma comparativa a outros atores do conservadorismo.

\section{CONCLUSÃO}

Ao final deste percurso, é possível perceber como a aparente contradição colocada no início deste artigo se explica tanto pela interpretação mais geral de Elide sobre o sentido da tradição em uma sociedade capitalista periférica, como pela própria formação intelectual da autora. Afinal, o interesse de Elide pelo marxismo de Lukács e Goldmann a levou ao estudo das relações entre processo social e forma literária. Isto é, tratava-se de apreender como os intelectuais estudados compunham, em seus ensaios e obras romanescas, os fragmentos de uma experiência marcada pela afirmação da ordem burguesa e seus efeitos desagregadores. A referência a Lukács e Goldmann também levava Elide a pensar o problema da totalidade, tema fundamental nessa variante do marxismo, o que fez com que os trabalhos da autora sobre os intelectuais vinculados ao pensamento social brasileiro sempre estivessem orientados por uma análise da relação entre as ideias desses agentes e a experiência política e histórica mais ampla na qual estivessem inseridos. Tal ângulo de análise é mais facilmente visível em As criaturas de Prometeu, em que a referência ao rearranjo político efetuado em I930 é fundamental para dar sentido ao modo como Freyre valorizava a tradição numa sociedade que se modernizava.

Ao centrar o foco nesses intelectuais da tradição, Elide provou que o dilema da ordem burguesa brasileira se radica na sua dimensão desigual e tradicional, em que o Antigo Regime se inscreve com força no contemporâneo, reivindicando um lugar próprio. Assim, interpretar o processo social brasileiro nos obrigaria a dar conta do atraso, entendido não como uma simples resistência destinada a desaparecer, mas como um ato político, que se repõe constantemente em novos arranjos sociais, marcando de forma indelével a cultura brasileira.

Sustento, também, que a obra de Elide nos faz perceber outro ponto fundamental do processo social brasileiro: ele não se revela facilmente por uma análise sociológica da vida material e/ou econômica, mas, sim, por uma investigação totalizante que dê relevo ao mundo da cultura e das ideias. Isto se dá 
porque nosso doloroso processo modernizador foi capaz de produzir elevados indicadores de crescimento econômico, transformando o país num dos mais industrializados do mundo, mas continuou a secretar dinâmicas sociais perversas. Numa sociedade em que a economia sempre parece estar encapsulada em processos políticos autoritários, estudar os intelectuais e os escritores é uma das melhores formas de desvendar os segredos do capital à brasileira. Pode-se relacionar tal argumento com a conhecida tese de Antonio Gramsci sobre o peso da superestrutura em sociedades marcadas pelo agrarismo, pela burocracia e pela hipertrofia do aparato estatal (Gramsci, 2002). Esta conexão, não explicitamente reivindicada pela autora, permite traçar uma ponte entre a obra de Elide e a de Luiz Werneck Vianna (I997), outro intérprete do pensamento social brasileiro de forte inspiração marxista. Tal conexão, longe de negar a originalidade e a potência das reflexões da socióloga da Unicamp, permite atestar a força e a diversidade dos estudos sobre o pensamento social, e sua centralidade para a investigação contemporânea dos processos de longa duração que constituíram o Brasil. Às novas gerações cabe renovar a reflexão a partir deste legado, para o qual Elide efetuou contribuição decisiva e fecunda.

Recebido em 22/04/20I5 | Aprovado em I I/05/20I5

João Marcelo E. Maia é doutor em Sociologia pelo Instituto Universitário de Pesquisas do Rio de Janeiro (IUPERJ), professor adjunto e coordenador de ensino de graduação do CPDOC/Escola de Ciências da Fundação Getulio Vargas-RJ. Seus principais interesses são: pensamento social brasileiro, história da sociologia e sociologia dos intelectuais. Entre suas últimas publicações, podem-se citar "History of sociology and the quest for intelectual autonomy in the Global South: the cases of Alberto Guerreiro Ramos and Syed Hussein Alatas" (20I4) e "Qual sociologia pública? Uma visão a partir da periferia”, em co-autoria com Fernando Perlatto (2013). 


\section{REFERÊNCIAS BIBLIOGRÁFICAS}

Araújo, Ricardo Benzaquen de. (I994). Guerra \& paz: a obra de Gilberto Freyre nos anos 30. Tese de Doutorado. Museu Nacional/UFRJ.

Arruda, Maria Arminda do Nascimento. (1995). A sociologia no Brasil: Florestan Fernandes e a "escola paulista". In: Miceli, Sérgio (org). História das ciências sociais no Brasil. São Paulo: Sumaré/Fapesp, p. 107-232.

Bastos, Elide Rugai. (2010). Octávio de Faria e a tragédia burguesa. In: Ferreira, Gabriela Nunes \& Botelho, André (orgs). Revisão do pensamento conservador: ideias e política no Brasil. São Paulo: Hucitec, p. 273-3ı.

Bastos, Elide Rugai. (2007). Conversas com o autor. Disponível em <https://www.youtube.com watch?v=8vW7j XT CMFE >. Acesso em I I mar. 2015.

Bastos, Elide Rugai. (2006a). As criaturas de Prometeu: Gilberto Freyre e a formação da sociedade brasileira. São Paulo: Global.

Bastos, Elide Rugai. (2006b). Paulo Augusto Figueiredo e o pensamento autoritário no Brasil. In: Ridenti, Marcelo; Bastos, Elide Rugai \& Rolland, Denis (orgs). Intelectuais e Estado. Belo Horizonte: Ed. UFMG, p. I2I-I42.

Bastos, Elide Rugai. (2003). Gilberto Freyre e o pensamento hispânico. Bauru, SP: Edusc.

Bastos, Elide Rugai. (2002). Pensamento social da escola sociológica paulista. In: Miceli, Sérgio (org). o que ler na ciência social brasileira, I970-2002. São Paulo/Brasília: Anpocs/Sumaré, p. I83-232.

Bastos, Elide Rugai. (1984). As Ligas Camponesas. Petrópolis: Vozes.

Chaguri, Mariana Miggiolaro. (2009). O romancista e o engenho: José Lins do Rego e o regionalismo nordestino dos anos de I920 e I930. São Paulo: Hucitec.

Cohn, Gabriel. (1978). O ecletismo bem temperado. In: D'Incao, Maria Ângela (org). O saber militante: Ensaios sobre Florestan Fernandes. São Paulo/Rio de Janeiro: Ed. Unesp/ Paz e Terra, p. 48-53. 
Fernandes, Florestan. (1975). A revolução burguesa no Brasil. Ensaio de interpretação histórico-sociológica. Rio de Janeiro: Zahar.

Fernandes, Florestan. (1965). A integração do negro na sociedade de classes. São Paulo: Companhia Editora Nacional.

Gramsci, Antonio. (2002). Os Cadernos do Cárcere. Risorgimento. Notas sobre a história da Itália. Rio de Janeiro: Civilização Brasileira (vol. 5).

LaCapra, Dominick. (I980). Rethinking intellectual history and reading texts. History and Theory, I9/3, p. 245-276.

Lahuerta, Milton. (I999). Intelectuais e a transição: entre a política e a profissão. Dissertação de Doutorado. FFLCH/Universidade de São Paulo.

Lukács, Georg. (2009 [I9I6]). A teoria do romance: um ensaio histórico-filosófico. São Paulo: Ed. 34.

Lukács, Georg. (2003 [1923]). História e consciência de classes. São Paulo: WMF Martins Fontes.

Lukács, Georg. (1968). Marxismo e teoria da literatura. Rio de Janeiro: Civilização Brasileira.

Medeiros da Silva, Mário Augusto. (2013). A descoberta do insólito: literatura negra e literatura periférica no Brasil (I9602000). Rio de Janeiro: Aeroplano.

Ridenti, Marcelo; Bastos, Elide Rugai \& Rolland, Denis (orgs.). (2006). Intelectuais e Estado. Belo Horizonte: Ed. UFMG. Schwarcz, Lilia Moritz \& Botelho, André. (20 I I). Simpósio: cinco questões sobre o pensamento social brasileiro. Lua Nova, 82, p. I39-I59.

Werneck Vianna, Luiz Jorge. (I997). O ator e os fatos: a revolução passiva e o americanismo em Gramsci. In: A revolução passiva: iberismo e americanismo no Brasil. Rio de Janeiro: Revan, p. 28-88. 
Palavras-chave

Elide Rugai Bastos; Pensamento social brasileiro;

Pensamento conservador; Marxismo; História da sociologia..

Keywords

Elide Rugai Bastos; Brazilian social thought; Conservative thought;

Marxism; History of sociology.

\section{OS SENTIDOS DA TRADIÇÃO: UM ESTUDO DE CASO NO PENSAMENTO SOCIAL BRASILEIRO}

\section{Resumo}

Este artigo analisa a obra da socióloga Elide Rugai Bastos e procura responder à seguinte questão: por que uma intelectual que combinou criativamente sociologia e marxismo se interessou pelo estudo de autores conservadores? O artigo analisa uma seleção de textos da autora dedicados ao estudo de intelectuais conservadores. A hipótese é de que o foco no estudo de ideias conservadoras explica-se pela própria dinâmica do processo modernizador brasileiro, no qual elementos tidos como parte da tradição nacional são atualizados de modo particular.

THE MEANINGS OF TRADITION: A CASE STUDY IN BRAZILIAN SOCIAL THOUGHT

\section{Abstract}

This article analyzes the works of the Brazilian sociologist Elide Rugai Bastos and seeks to answer the following question: why did an intellectual who creatively combined sociology and Marxism focused on conservative authors? The article analyzes some of the author's texts that focus on the ideas of conservative intellectuals. This focus can be explained by the dynamics of Brazilian modernizing process, in which elements associated to the Brazilian tradition are renewed in a peculiar way. 